\title{
Transição da Administração Pública nos Estados Unidos
}

\begin{abstract}
Aula inaugural dos Cursos de Administração Pública, proferida pelo Professor A. Gaylord Obern, da Universidade da California clo Sul, na Faculdade de Ciências Econômicas da Universidade do Rio Grande do Sul, em 10 de março de 1960.
\end{abstract}

É um prazer comemorar o início de outro ano de estudo da administração pública sob os auspícios da Universidade do Rio Grande do Sul. O curriculo, aqui, é paralelo à experiência que tivemos nos Estados Unidos, no desenvolvimento de cursos para funcionários públicos. Como em qualquer parte de um pais, o desenvolvimento da prática e do estudo da administração pública nos Estados Unidos seguiu uma trilha, até certo ponto peculiar, de acôrdo com suas necessidades. Muito se pode aprender da experiência alheia, rão apenas em assuntos pessoais mas também em assuntos de estado. Desta maneira, pode-se sugerir melhorias que se adaptem às condiçốes locais. Espero poder aprender alguma coisa sôbre o sistema administrativo do Brasil durante minha permanência aqui, e talvez esta minha palestra de hoje seja uma oportunidade de compartilhar com os senhores a minha opinião sôbre a experiência norte-americana em administração pública.

Tendo em vista os meus objetivos para hoje, limitarei meus comentários às dez áreas maiores em que tenha havido uma mudança sensivel no estudo e na prática da administração pública nos Estados Unidos. A seguir, peço permissão para mencionar algumas outras áreas onde continuamos a ter dificuldades. As soluções para êstes problemas não serão obtidas nem rápida nem fàcilmente, mas sim através do processo da evolução - por adaptação, descoberta, educação!

Uma das mudanças mais notáveis, que ocorreu nos Estados Unidos, foi a tendência de abandonar o tipo de administração baseado no «administrador» para adotar o método «focalização do empregado» a fim de fazer funcionar uma organização. Segundo o velho método organizacional, todos os recursos, teorias e princípios de administração tinham em vista a melhoria das técnicas administrativas do supervisor. Aquêle método destacava o manejo dos empregados pelo chefe, assim como os fantoches são controlados por seu operador. O conceito precipuo era: «O que é bom para a organização. é bom para o empregadol». Ao redor dessas atitudes básicas desenvolveu-se tôda uma série de princípios, visando a tornar o trabalho do chefe mais. eficiente: delegação de autoridade, limite do alcance do contrôle, linha 
«staff», unidade de comando, tarefas homogêneas, etc. Com o aproveitamento de todos os elementos disponíveis durante a Segunda Guerra mundial, as perspectivas dos primeiros desbravadores da psicologia, tornaram-se mais importantes para a administração. Já que os indivíduos se tornavam cada vez mais escassos no mercado de trabalho, mais atenção foi dada às necessidades e desejos, e os princípios gerais da moderna psicologia foram aplicados a fim de se obter a melhor utilização, chegando-se ao ponto de alterar a estrutura organizacional para acomodar incompatibilidades de individuos. O novo lema passou a ser: «O que é bom para o empregado, é bom para a organização!». O subordinado, e não o seu superior, passou a ser o foco da atenção e do estudo. A psicologia, a sociologia e a matemática passaram a ser cada vez mais utilizadas para auxiliar a análise dos problemas adminis trativos. Esta tendência culminou no movimento da «administração Democrática», atualmente ativo, e que conta com muitos simpatizantes e com não tantos executantes.

A segunda mudança importante no pensamento administrativo nos Estados Unidos, nos últimos 50 anos, é o reconhecimento de que a administração pública e a política não podem ser distinta e eternamente separadas. Inicialmente, no estudo e na prática da administração pública, pensou-se que era dever do administrador meramente executar as leis aprovadas pela legislativo, ser um técnico e nâo envolver-se em problemas de política geral. Isto teve por resultado desenvolver (talvez demasiado cedo) uma série de principios estanques de administração, estabelecidos primàriamente com 0 objetivo de executar tarefas pré-determinadas. Vir a envolver-se em politica era algo de perigoso para um administrador público. Com o crescimento das funções do govêrno, repercutindo em todos os setores da vida econômica e exigindo uma determinação detalhada da politica legislativa do govêrno, com a atividade crescente de grupos organizados para fazer pressão tanto sôbre o Poder Executivo como sôbre o Poder Legislativo, e com a verificação, por parte do Legislativo, que a administração das leis poderia ter maior importância que stia formulação, a politica envolveu-se na administração pública. Reconhecendo a inutilidade daquela dicotomia anteriormente existente, estas novas relações foram ràpidamente legitimadas pelos teóricos e pelos autores. Como resultado, a administração pública hoje em dia se expande de forma a incluir êstes elementos determinantes das normas políticas, tais como o legislativo e - executivo, grupos de pressão, partindo de políticos, opinião pública, etc. $\mathrm{Na}$ verdade, todo o âmbito das atividades do govêrno está englobado no processo administrativo. Esta tendência, felizmente, coincide com o desenvolvimento similar dos recursos de pesquisas e análise das ciências sociais, tanto para o estudante como para o executante.

Uma terceira tendência é o deslocamento da ênfase, no treinamento de administradores públicos, do estudo de recursos minuciosos e técnicas do processo administrativo para o preparo do que se chama de «generalistas de administração». Anteriormente, os programas educacionais eram organizados de forma a prover especialistas nas operações de govêrno - agente de compras, administradores de pessoal, contadores, auditores, etc. Com efeito, as Universidades empreenderam o tipo de treinamento que subseqüentemente foi reconhecido como dever fundamental do próprio govêrno, através de seus 
programas de treinamento em serviço. Correntemente, os programas de administração pública nas Universidades estão treinando administradores públicos a terem uma visão global da administração - perspectiva esta que é adquirida vagarosamente quando se ocupa uma posição especializada no serviço público. Dá-se ênfase à compreensão geral dos grandes processos, técnicas e especialidades, de maneira que cada elemento possa ser chamado para resolver o problema com que se depara o administrador-geral. Afortunadamente, êste desenvolvimento começou ao mesmo tempo que os podêres públicos dos Estados Unidos passaram a ter um bom conceito dêstes jovens treinados para se tornarem os administradores de amanhã, atitude esta acompanhada por medidas práticas consubstanciadas no seu recrutamento.

O programa visando a empregar êstes administradores gerais tem tido grande sucesso no govêrno federal dos Estados Unidos e estudos subseqüente têm indicado que êstes indivíduos atingem mais ràpidamente posições de responsabilidade do que aquêles que entraram no serviço público sem êste tịpo de formação.

Um quarto desenvolvimento destacado nos Estados Unidos durante êstes últimos 50 anos, é a crescente profissionalização do serviço público em todos os níveis do govêrno. Aquela calamitosa situação existente no século XIX, em conseqüência de um sistema de excessivo apadrinhamento, foi sendo modificada e o serviço público lentamente atingiu fôro de organização precipuamente pelos seus próprios esforços no sentido de evitar a corrupção, aumentar sua receptividade para com as mudanças de programa dos diferentes partidos políticos e aumentar a sua própria eficiência. $O$ serviço público tornou-se um lider no desenvolvimento de novos métodos de administração, novos métodos que são adotados pelas emprêsas privadas. Uma outra expressão de șua profissionalização, é o desenvolvimento de uma associação profissional muito ativa, com o objetivo primordial de desenvolver o estudo e melhorar a prática da administração pública. Não houve participação apenas de novos métodos de administração através desta organização, mas também começou-se a desenvolver padrões profissionais. Assim como aconteceu com o desenvolvimento da profissão dos médicos e dos advogados, a profissão de administrador público está se tornando mais reconhecida como um elemento necessário na sociedade hodierna.

Quinto, a estrutura do ramo executivo do govêrno sofreu também uma mudança lenta mas perceptível. Quando um elemento poderoso da administração era temido no século XIX, o seu contrôle, de executivo, sôbre o pessoal, finanças, organização, etc., era severamente restringido. Unidades organizacionais separadas (responsáveis perante ao legislativo ou aos eleitores) eram coisas habituais. Com o reconhecimento da necessidade de uma direção eficiente e responsável, o Século XX viu a consolidação dessas diversas unidades sob o contrôle direto de um único funcionário de chefia executiva. Não mais se considera desejável ter um administrador que não tenha contrôle sôbre todos os elementos da administração. No entanto, o temor morre lentamente, assim como os seus reflexos na organização. Mas cada vez mais, desenvolve-se a organização executiva consolidada. 
Em seguimento, as responsabilidades da administração eficiente de pessoal dependem, cada vez menos, da intervenção de um setor centralizado de pessoal. Existe uma tendência distinta para descentralizar as funções de pessoal, atribuindo-as a unidades individuais do govêrno, diretamente envolvidas com atividades de pessoal. Os vestígios aquêle movimento contrário ao sistema de apadrinhamento, continuam a ser percebidos, no entanto. Especificamente, o grupo imparcial de julgamento de recursos de funcionários públicos sobreviverá a esta mudança. Com esta exceção, descentralização do contrôle de pessoal vem continuando desde a Segunda Guerra Mundial, quando a sistema centralizado tornou-se inútil. Esta tendência provàvelmente continuará a ponto de atribuir-se ao supervisor deveres que eram anteriormente atribuição dos especialistas de pessoal. Com êste desenvolvimento, completamos o círculo da teoria e da prática - partindo do método de organização centralizada para proteger o funcionário público dos excessos do seu supervisor, chegando de retôrno até o ponto onde todos os elementos da administração efetiva de pessoal começam no nivel de execução. Um dos desenvolvimentos mais recentes nos Estados Unidos é a aceitação do sistema de orçamento do programa ou «perfomance budgeting». Anteriormente, o orçamento era feito na base de itens especificos a serem comprados -- cadeiras, prédios, papel, etc. A primeira comissão Hoover que examinou em detalhe todo o processo administrativo do govêrno federal dos Estados Unidos, desde 1947, recomendou que um método de orçamento muito mais significativo deveria decidir o que cada programa ou projeto de govêrno pudesse custar e abrir créditos nestas bases, em vez de fazer uma estimativa detalhada de pessoal e material necessários para a execução do programa. Êste novo sistema foi adotado por todos os maiores departamentos do Govêrno Federal dos Estados Unidos, assim como por outros setores do serviço público. Este novo sistema não sòmente dá maior flexibilidade para o administrador, mas permite também ao legislativo exercer um contrôle mais sig nificativo das atividades do govêrno.

Desde a grande expansão do Govêrno após 1940, os Estados Unidos vêm observando um grande aumento na utilização de consultores privados para auyiliar a resolver os diferentes problemas administrativos do Govêrno. Grupos de especialistas são contratados para examinar e fazer recomendações à respeito de um problema que não pode ser resolvido pelos próprios administradores. Isto poderia ter sido causado pela falta de experiência em resolver os problemas, falta de pessoal treinado para encetar a investigação, ou a existência de fatôres emocionais ou pessoais que impediriam resolver imparcialmente o problema. É também importante o fato de que se obtêm fundos, com maior facilidade, para uma investigação específica do que para a implantação de um serviço de organização e métodos que requereria dotações orçamentárias anuais e apoio diário do chefe executivo.

Concomitantemente, com o crescimento dos consultores privados, houve a diminuição das funções de organização e métodos no govêrno. É muito ma1s fácil pedir-se a alguém que resolva os nossos problemas do que tratar de resolvê-los nós mesmos! Inevitàvelmente esta tendência será modificada e os primeiros vestígios de tal mudança já podem ser vistos com o desenvolvimento da «engenharia de administração visando a integrá-la na administração pública. 
Por fim, os administradores públicos dos Estados Unidos estão se tor nando cônscios de que um cientista realizando pesquisa no laboratório, necessita de um alto grau de independência dos contrôles do govêrno. Este é o dilema que os administradores públicos norte-americanos estão começando a ver mais claramente. Por um lado, as fronteiras do conhecimento são largadas através de um processo que exige o máximo grau de liberdade para o cientista criador. Por outro lado, as condições do serviço do govêrno impõem para todos os funcionários do Poder Executivo (inclusive os cientistas) alguma medida de responsabilidade, de modo a acomodar suas ações aos contrôles administrativos. Novas técnicas de administração pública estão sendo estabelecidas, permitindo solucionar êste dilema. Como base dessas novas técnicas está a adoção dos mais recentes métodos democráticos de administração, mais em consonância com as tradições científicas da pesquisa do que o velho método de tipo mais autoritário. Mais uma vez, uma mudança de um aspeto da administração pública acarretou um impacto em outro setor importante.

Permitam-me agora fazer uma lista de algumas áreas aonde continuamos a sofrer dificuldades:

1\%) Como coordenaremos um superproliferado sistema de unidades «staff» especializadas? Quem coordenará os coordenadores?

$2^{9}$ ) Pode-se desenvolver uma ciência de administração pública ou deve ela continuar apenas uma arte?

3) É possível estabelecer um código de ética para o serviço público, que seja prático?

40) Quais os métodos mais eficientes para trabalhar com os legisladores, partidos politicos, grupos de pressão, etc? politicos?

$5^{\circ)}$ Em que nivel devem os administradores ser indicados por motivos

6) Como podem os funcionários públicos ser politicamente ativos em sua vida privada sem envolver-se em ações administrativas facciosas?

$8^{\circ}$ ) Como pode trabalhar o govêrno federal mais eficientemente, com os governus estaduais e municipais, afim de resolver problemas mútuos?

$9^{\circ}$ ) Como se poderá manter elementos subversivos afastados do serviço público sem ferir o sistema dos direitos individuais?

10\%) Como pode a lei administrativa ser feita imparcialmente, quando os organismos do govêrno com elas envolvidos tenham interêsses escondidos?

Esta breve revisão mostra os maiores desenvolvimentos da administração pública nos Estados Unidos e indica que necessitamos que o progresso do passado continue no futuro! É através de um programa como o que os senhores estão iniciando hoje, que lhes será possivel encontrar soluções para os seus próprios problemas, do mesmo modo como fizemos nos Estados Unidos. 